\title{
PSICOLOGIA CULTURAL E MUDANÇA SOCIAL
} CULTURAL PSYCHOLOGY AND SOCIAL CHANGE

\author{
Fernando Lacerda Júnior \\ Universidade Federal de Goiás, Goiânia, Brasil
}

\section{Psicologia cultural e mudança social}

O livro Cultural psychology: A perspective on psychological functioning and social reform, de Carl Ratner - diretor do Institute for Cultural Research and Education na Califórnia nos EUA -, marca um giro na obra do autor de uma preocupação epistemológica e metodológica ${ }^{1}$ para uma discussão direta sobre processos de mudança social ${ }^{2}$. A trajetória intelectual do autor remonta aos anos 70, quando publicou trabalhos sobre R. D Laing e críticas ao behaviorismo e ao humanismo no periódico Telos (Ratner, 1967, 1971) - que realizou importante trabalho de divulgação de textos de Theodor Adorno, Michel Foucault, Jean-Paul Sartre e outros. Recentemente, Ratner vem estudando as contribuições de Vygotsky e da Psicologia Cultural.

Dividido em quatro partes (sete capítulos e epílogo), o livro busca: (a) reconceitualizar a psicologia, relacionando fatores macroculturais (FMCs) e psicologia humana; (b) discutir a aplicação da psicologia macrocultural (PMC) na pesquisa científica, na reforma social ${ }^{3}$ e na psicoterapia. Ratner tem como principais bases filosóficas a dialética e o funcionalismo, sendo influenciado por um amplo espectro de estudos: marxismo (Marx, Engels, Sartre, Marcuse e Fromm), psicologia histórico-cultural (Vygotsky, Luria e Leontiev), abordagem ecológica de Bronfenbrenner, psicologia cultural, história social, sociologia estruturalista, antropologia e outros autores.

A PMC é apresentada como uma nova teoria geral da psicologia que busca uma compreensão científica da psicologia humana com o fim de transformar a cultura para que problemas psicológicos sejam superados. A PMC politiza a psicologia, redefinindo o seu objeto de análise e as suas possibilidades de intervenção. Por isso, boa parte do livro dedica-se à apresentação da PMC, à crítica de outras abordagens na psicologia - psicologia predominante (mainstream psychology), psicologia intercultural (cross-cultural psychology), psicologia evolucionária, psicologia cultural e outras - e à exposição de estudos que fundamentam a proposta de uma PMC. Essa, para o autor, tem uma única suposição básica:

Como os fatores macroculturais são os meios pelos quais os seres humanos sobrevivem e se realizam, os fenômenos psicológicos buscam construí-los, mantê-los e refiná-los. Assim, para estabelecer, manter e refinar uma instituição social (como uma escola, uma igreja, um governo ou um local de trabalho), um artefato (como dirigir um carro em uma via expressa de Los Angeles, preparar o solo com uma enxada, caçar com arco e flecha, vestir uma mini-saia ou um corpete), ou um conceito cultural (como a constituição do tempo enquanto unidades discretas e mensuráveis, um conceito filosófico de existencialismo, cálculo ou a sonata como gênero musical), as pessoas devem desenvolver formas particulares de pensar, perceber, aprender, sentir e de autoconceito. Estes fenômenos psicológicos devem ter a forma e o conteúdo dos macro-fatores que eles constroem, mantém e refinam. (Ratner, 2006, p. 14)

Nessa concepção, fenômenos psicológicos são funções culturais, "a psicologia é um mecanismo cultural" (p. 15). Para Ratner, a cultura é um complexo constituído por três FMCs básicos: instituições sociais e políticas, conceitos culturais e infraestrutura física e artefatos. Um dado fator é definido como macrocultural pela sua capacidade de determinar a existência social. A função dos FMCs é superar limitações individuais, articulando coletivamente os seres humanos para garantir a reprodução social da existência individual.

Seres humanos constroem instituições sociais, artefatos e conceitos para superar as limitações de forças, conhecimento, informação sensorial e habilidades corporais. Macroestruturas combinam a potência, o conhecimento, as habilidades e a criatividade de muitas pessoas em ações sociais, físicas e conceituais coordenadas. Assim, as pessoas tornam-se membros de macroestruturas, tornam-se indivíduos socialmente estruturados (p.41).

FMCs constituem uma estrutura organizada que mudam em suas formas e seus conteúdos em cada formação social concreta. Para que FMCs sejam planejados, mantidos, coordenados ou transformados é preciso que existam fenômenos psicológicos congruentes com eles. Se na natureza o comportamento animal é governado por processos instintivos, na cultura o comportamento humano é governado por processos psicológicos. Em outras palavras, o desenvolvimento dos fenômenos psicológicos foi engendrado pelos FMCs, os primeiros são os meios especificamente sociais de operar os últimos. A psicologia humana funciona como fenômeno que possibilita a cultura ser apropriada pelo indivíduo 
e, assim, guiar seu comportamento - o que não elimina a transformação dos FMCs por grupos.

A meta da PMC é compreender a relação entre fenômenos psicológicos e FMCs. Com isso, Ratner argumenta que uma divisão da psicologia em diversos setores é desnecessária ou até indesejada: “A psicologia macrocultural é uma teoria científica geral que explica a natureza cultural dos fenômenos psicológicos" (2006, p. 133$)^{4}$. A PMC é uma ciência social que não possui barreiras rígidas com outras ciências sociais, pois a relação entre psicologia e cultura marca a existência de toda relação entre indivíduo e sociedade.

De acordo com Ratner, cabe à PMC identificar como FMCs engendram, organizam e determinam fenômenos psicológicos, mas o autor reconhece que a predominância dos fatores culturais sobre os fatores pessoais pode resultar em um mecanicismo que não apreende a integração dialética entre FMCs e psicologia humana. Para evitar isso, o autor propõe a pesquisa qualitativa como a metodologia da PMC. Dessa forma, com a finalidade de elucidar os aspectos culturais dos fenômenos psicológicos, a atividade de pesquisa da PMC tem como foco central a investigação qualitativa da psicologia individual na vida cotidiana. O processo de pesquisa busca apreender quais características de instituições, conceitos e artefatos estão presentes nos fenômenos psicológicos e, por isso, ela parte da formulação de hipóteses sobre origens, funções e traços macroculturais dos fenômenos psicológicos.

Para Ratner, a metodologia não soluciona problemas teóricos, mas está subordinada às elaborações ontológica e epistemológica. Por isso, os dados empíricos sempre são complementares às elaborações teóricas. Por exemplo, há uma discussão sobre a emergência histórica dos fenômenos psicológicos que explica como cada formação social cria uma cultura que funciona como "ímpeto" para o desenvolvimento de certos fenômenos psicológicos que, por sua vez, são cruciais para a manutenção da cultura. FMCs estruturam a experiência e o sentido de vida das pessoas, assim como estabelecem os conceitos pelos quais elas definem e interpretam coisas. Essa discussão é complementada com alguns dados de pesquisas empíricas e estudos históricos: o surgimento da linguagem coincide com a produção de artefatos no Paleolítico Superior, enquanto o surgimento de operações linguísticas complexas (escrita, matemática etc.) coincide com a complexificação da produção de artefatos na Revolução Neolítica; o funcionamento cerebral demonstra que o número de sinapses e de neurônios é dependente das experiências humanas; as mudanças econômicas da Inglaterra nos séculos XVI e XVII engendraram o conceito de responsabilidade pessoal etc.

Após apresentar formulações sobre a relação entre FMCs e fenômenos psicológicos, Ratner discute a articu- lação da PMC com a reforma social e a psicoterapia. Para o autor, a intrínseca relação entre fenômenos psicológicos e FMCs articula crescimento psicológico com reforma social. A PMC busca explicar e mudar essa relação: “A Psicologia Macrocultural empreende uma aprofundada análise dos problemas psicológicos para identificar quais são seus aspectos culturais, o papel que eles desempenham (como eles operam) na organização da psicologia e se é necessário reformulá-los" (p. 179).

Ratner propõe um modelo de cinco passos para a PMC contribuir com a reforma social: (a) identificar, em uma dada população, quais fenômenos psicológicos são satisfatórios (fulfilling) ou insatisfatórios (unfulfilling); (b) decompor cada fenômeno psicológico em componentes psicológicos elementares; (c) identificar os FMCs determinantes na constituição de cada componente psicológico; (d) propor a promoção dos FMCs que produzem fenômenos psicológicos satisfatórios e (e) propor a eliminação/transformação de FMCs insatisfatórios.

Um FMC nocivo (deleterious) não existe isoladamente, e a sua transformação com o fim de eliminar fenômenos psicológicos insatisfatórios exige a mudança de seu contexto de apoio (outros FMCs). Não basta mudar elementos isolados ou fazer mudanças meramente quantitativas. A reforma social demanda mudanças qualitativas e estruturais para superar o sofrimento psicológico.

Ratner dá vários exemplos sobre como seu modelo de cinco passos pode lidar com diversos problemas psicológicos. Um exemplo: raiva pessoal (personal anger) é analisada como produto de um autoconceito individualista que culpabiliza, unilateralmente, indivíduos por suas ações. Esse autoconceito, por sua vez, é produto do conceito cultural de autonomia pessoal, que brotou de práticas econômicas capitalistas privadas - o que se relaciona com o fato da raiva pessoal ser um problema mais generalizado em uma sociedade como os EUA. Superar tal conceito cultural, com o fim de criar um novo sentido de eu (self), implica elaborar e promover novos FMCs, isto é, novas instituições sociais, novos conceitos culturais e artefatos. É preciso mudar relações capitalistas de mercado, promover nova ideologia política, criar e difundir novos conceitos culturais por meio de programas de TV etc. Em síntese, uma reforma social generalizada atingindo diversos FMCs.

Ratner reconhece que esse tipo de mudança não ocorre de forma automática, por isso, apesar de afirmar que as únicas mudanças psicológicas duradouras são aquelas alcançadas mediante reforma social, ele afirma que a PMC pode ser importante para as pessoas enquanto não existem reformas sociais. Tal como no caso anterior, o autor propõe um modelo de trabalho voltado principalmente para o campo da psicoterapia, mas que pode ser usado para toda busca de crescimento psicológico sem reforma social - constituído por seis 
passos: (a) demonstrar para a pessoa ou o grupo que um problema psicológico é função de FMCs, (b) decompor o problema psicológico em seus diversos componentes psicológicos, (c) estabelecer as relações entre cada componente e os FMCs, (d) contribuir para a pessoa criticar e evitar FMCs que produzem problemas psicológicos, (e) fazer com que a pessoa conviva com FMCs que promovem um funcionamento psicológico positivo e (f) encorajar a pessoa a se engajar politicamente para alterar FMCs nocivos e desenvolver FMCs satisfatórios.

Além da elaboração teórica sobre a PMC, o livro critica diversas abordagens da psicologia, especialmente a psicologia predominante de corte positivista. Essa é criticada por tomar os fenômenos psicológicos com construtos teóricos individualistas, universalizantes e naturalizantes que obscurecem o papel da cultura e a dimensão histórica de todo fenômeno psicológico. Tal concepção de psicologia explica a hegemonia do positivismo, apesar das suas limitações políticas e científicas - para defender essa tese, o autor analisa um amplo leque de construtos psicológicos (agressividade, adolescência etc.), que não é possível detalhar aqui.

Ratner também critica a psicologia evolucionária por tentar explicar o comportamento humano no contexto cultural usando os mesmos princípios teóricos explicativos do comportamento animal na natureza, perdendo de vista o caráter único da cultura e as suas vantagens adaptativas que são determinantes da vida social.

Outro alvo de críticas são algumas abordagens psicológicas da cultura como a psicologia intercultural e a psicologia cultural individualista. A primeira é criticada por ser mera aplicação da psicologia predominante e positivista ao estudo de culturas diferentes. Já a segunda é criticada por ser abordagem subjetivista que define a cultura como produto de significados e sentidos dos indivíduos nas suas microinterações cotidianas, hipertrofiando, assim, o papel da subjetividade - usualmente reduzida à sua dimensão simbólica - na história. Ratner ainda critica o construcionismo social enquanto filosofia da ciência e reivindica o realismo crítico como filosofia da ciência crucial para uma ciência que seja guiada pela busca de objetividade, verdade e conhecimento da realidade, ao invés do irracionalismo hegemônico nos círculos críticos contemporâneos.

Em síntese, o presente livro de Carl Ratner é uma introdução a diversos estudos e polêmicas em um campo relativamente novo da psicologia que possibilita aprofundar o questionamento de algumas afirmações generalizantes e a-históricas sobre a natureza humana. No entanto, se é interessante a proposta de relacionar psicologia e mudança social, é preciso apontar alguns dos principais problemas das proposições presentes no livro.

Primeiramente, é preciso avaliar se a criação de uma nova ciência é passo necessário para validar a necessidade da mudança social e, assim, determinar os rumos das lutas políticas por mudanças sociais. $\mathrm{O}$ modelo de cinco passos que liga reforma social e PMC termina em uma proposta de mudar todas as instituições, criar novos conceitos e uma nova infraestrutura para as sociedades contemporâneas que também está presente em todo programa político revolucionário, cuja realização histórica vai muito além dos limites de uma ciência. Ainda que as análises propostas sejam melhores do que aquelas predominantes na psicologia, o fato é que a própria demonstração do autor sobre a subordinação dos fenômenos psicológicos aos FMCs indiretamente indica que a tentativa de dar à PMC um papel central na reforma social pode ser um exagero sobre as possibilidades da psicologia como ciência e profissão.

A noção de cultura desenvolvida pelo autor parece ser extremamente ampla e, em alguns momentos, forçosa. Por exemplo, é difícil concordar com a afirmação de que foram FMCs que levaram ao desenvolvimento da linguagem, já que não há como conceber cultura sem linguagem. Apesar de isso não invalidar a ideia geral de que os fenômenos psicológicos se desenvolveram ao longo da história dos seres humanos em um processo evolutivo, a utilização da categoria cultura para explicar esse processo é, em alguns momentos, inadequada.

Além disso, os modelos de cinco e seis passos de aplicação da PMC à reforma social e à psicoterapia são apresentados por Ratner de forma muito geral. Ainda que as ideias que permeiam essa tentativa sejam importantes, seria interessante encontrar análises mais aprofundadas. São deixados de lado problemas cruciais, como a definição sobre o que seria um fenômeno psicológico satisfatório ou insatisfatório - a única resposta esboçada por Ratner para esse complexo problema é superficial:

Para os propósitos deste livro, assumirei que a maioria concordará que fenômenos psicológicos insatisfatórios incluem irracionalidade, agressão, preconceito, stress, solidão, conformismo, inteligência baixa, dificuldades de aprendizagem, incapacidade de concentração, confusão, egocentrismo, autoritarismo, apatia, alienação, depressão, paranoia, tendências suicidas e atributos relacionados. Satisfação psicológica é a oposição àqueles. (2006, p. 170)

Esse ponto revela a principal fragilidade da teorização do autor: apesar de suas críticas ao positivismo e à psicologia dominante, o autor não rompe com o funcionalismo - que é apresentado como uma das duas bases filosóficas fundamentais da PMC. O funcionalismo, tal como é apresentado por Ratner, é um tipo de análise que busca estudar um fenômeno ou coisa por meio de sua função. A análise da função de um elemento no interior de um sistema revela o que ele é, por que ele existe e quais são suas propriedades. Só é possível explicar um fenômeno por meio da análise de sua função. Todo 
sistema social é integração de elementos que se interpenetram para fazer o primeiro funcionar. A mensagem conservadora é clara: cada componente de um sistema tem um papel que permite o sistema funcionar; se há um desequilíbrio, então se deve buscar o componente que causa tal desequilíbrio.

Ratner reconhece essa função conservadora da análise funcionalista, mas acredita que, ao introduzir o elemento da contradição - que é proveniente de sua segunda base filosófica, a dialética -, o funcionalismo deixa de ser conservador: a dialética mostra que um sistema é uma unidade-de-diferenças que funciona contraditoriamente e, assim, produz mudanças. Dessa forma, o papel da dialética na PMC de Ratner é o de um corretivo ao funcionalismo ${ }^{5}$.

Essa concepção está presente nos modelos de análise propostos por Ratner. A questão central é classificar os fenômenos como psicologicamente realizadores ou não e localizar que função eles desempenham na cultura. Porém, no momento da análise concreta, Ratner não oferece uma análise teórica sobre o que seriam fenômenos psicológicos satisfatórios ou não - apenas espera uma disposição do leitor a concordar com algumas de suas suposições.

Pode-se afirmar que algumas das respostas dadas por Ratner são muito gerais e, até mesmo, simplistas. Mas isso não elimina a importância desse interessante livro sobre "Psicologia Cultural", que dá bases teóricas para se entender fenômenos como anorexia, depressão, loucura, síndrome do pânico etc. enquanto experiências culturalmente específicas que podem ser transformadas somente quando as suas raízes sociais forem tocadas. Há uma revisão bibliográfica importante que está aliada com a demonstração da centralidade de uma abordagem histórico-genética para o estudo de fenômenos psicológicos e da importância da elaboração teórica na escolha de métodos de pesquisa.

\section{Notas}

1 Pelo menos três livros (Ratner, 1995, 1997, 2002) representam essa preocupação mais teórica.

2 Além do livro aqui resenhado, algumas publicações mais recentes do autor, focam diretamente as questões ligadas à relação entre psicologia e mudança social (ver Ratner, 2007, 2009).

3 Talvez uma tradução melhor para "social reform " seria "mudança social". No entanto, como essa expressão, usualmente, é utilizada para "social change", optou-se por uma tradução mais literal.
4 Cabe notar o paralelo entre esta tentativa de construir uma "psicologia geral" e as diversas elaborações teóricas que buscam construir uma teoria unitária da psicologia. Essas tentativas são ainda mais intensas por teóricos que tomam como fonte de inspiração as discussões de Lev S. Vygotsky.

5 A dialética, com certeza, realiza análise da função social dos fenômenos sociais. No entanto, é em um sentido completamente diferente do funcionalismo. A função social, na dialética, revela a particularidade, mas não a determinação histórica de um fenômeno social.

\section{Referências}

Ratner, C. (1967). The critical psychology of R. D. Laing. Telos, 5, 98-114.

Ratner, C. (1971). Principles of dialectical psychology. Telos, 9, 83-109.

Ratner, C. (1995). A Psicologia sócio-histórica de Vygotsky: aplicações contemporâneas (L. L. Oliveira, Trad., $1^{\mathrm{a}}$ ed.). Porto Alegre: Arte Médicas.

Ratner, C. (1997). Cultural Psychology and Qualitative Methodology: theoretical and empirical considerations ( $1^{\mathrm{a}}$ ed.). New York: Plenum Press.

Ratner, C. (2002). Cultural psychology: Theory and method. New York: Plenum Press.

Ratner, C. (2006). Cultural psychology: A perspective on psychological functioning and social reform. London: Lawrence Erlbaum Associates.

Ratner, C. (2007). The cooperative manifesto: Social philosophy, economics, and psychology for co-operative behaviour. Journal of Co-operative Studies, 40(3), 14-26.

Ratner, C. (2009). O que é psicologia da libertação? É psicologia cultural. In R. S. L. Guzzo \& F. Lacerda Jr. (Orgs.), Psicologia social para América Latina: o resgate da psicologia da libertação (pp. 305-314). Campinas: Alínea.

Recebido em: 13/07/2009

Revisão em: 05/09/2009

Aceite final em: 15/09/2009

Fernando Lacerda Júnior é Professor adjunto de Psicologia Social da Faculdade de Educação da Universidade Federal de Goiás. Endereço: Rua 235, s/n. Faculdade de Educação, Universidade Federal de Goiás. Setor Leste Universitário. Goiânia/GO, Brasil. CEP: 74605-050. Email: Fernando_lac@yahoo.com.br

\section{Como citar:}

Lacerda, F., Jr. (2011). Psicologia cultural e mudança social. Psicologia \& Sociedade, 23(1), 197-200. 